\title{
Frequência de lesões macroscópicas em carcaças de bovinos reagentes ao teste tuberculínico
}

\section{Frequency of macroscopic lesions in cattle positive to the tuberculin skin test}

\author{
Mariana Assunção de Souza1 *, Nadia Grandi Bombonato', Pollyanna Mafra Soares' Gabriela Bim \\ Ramos', Mariane Pacheco dos Santos', Muriell Ribeiro Ganda', Anna Monteiro Correia Lima-Ribeiro'
}

| | | | | | | | | | | | | | | | | | | | | | | | | | | | | | | | | | | | | | | | | | | | | | | | | | | | | | | | | | | | | | | | | | | | | | | | | | | | | | | | | | | | | | | | | | | | | | | | | | | | | | | | | | | | | | | | | | | | | | | | | | | | | | | | | | | | | | | | | | | | | | | | | | | | | | | | | | | | | | | | | | | | | | | | | | | | | | | | | | | | | | | | | | | |

RESUMO: O objetivo deste trabalho foi analisar a frequência de lesóes macroscópicas sugestivas de tuberculose em carcaças de bovinos reagentes ao teste intradérmico de tuberculose. Os animais do estudo foram provenientes de rebanhos de exploração leiteira, localizados nos municípios de Perdizes, Patos de Minas, Lagoa Formosa e Uberlândia, Minas Gerais. Foram avaliadas 140 carcaças de bovinos positivos no teste cervical comparativo. Durante o abate sanitário foi realizada inspeçáo post mortem das carcaças, e as lesōes macroscópicas sugestivas de tuberculose foram registradas. Foram avaliados os linfonodos mediastínicos, fígado, pulmão e carcaça. Dos 140 bovinos examinados, 78 (55\%) apresentaram algum tipo de lesão macroscópica sugestiva de tuberculose, 38 (49\%) ocorreram exclusivamente nos linfonodos mediastínicos, 22 (28\%) no fígado e 11 (14\%) no pulmão; 5 (6\%) carcaças apresentaram lesôes no fígado, pulmão e linfonodo mediastínico, e 2 (4\%) tiveram lesóes no pulmão e linfonodo. Concluem-se que as lesóes não visualizadas em bovinos reagentes ao teste tuberculínico podem ocorrer e estariam relacionadas principalmente ao estágio de evolução da doença, tempo insuficiente na inspeção post mortem para detecção, bem como reaçóes inespecíficas para outras micobactérias.

PALAVRAS-CHAVE: Mycobacterium bovis; abate; diagnóstico intradérmico.

\begin{abstract}
The aim of this study was to analyze the frequency of macroscopic lesions suggestive of tuberculosis in cattle reacting to the tuberculin test. Cattle of this study were from dairy herds located in the cities of Perdizes, Patos de Minas, Lagoa Formosa and Uberlândia, Minas Gerais, Brazil. We evaluated 140 cattle carcasses positive to the cervical comparative intradermal tuberculin test. During the slaughter a post-mortem inspection of carcasses was done, and the lesions suggestive of tuberculosis were recorded. We evaluated the mediastinal lymph nodes, liver, lung and carcass. Of the 140 cattle examined, 78 (55\%) carcasses had some kind of macroscopic lesions suggestive of tuberculosis, 38 (49\%) occurred only in the mediastinal lymph nodes, 22 (28\%) in the liver and 11 (14\%) in the lungs; $5(6 \%)$ carcasses showed lesions in liver, lungs and lymph node, and $2(4 \%)$ showed lesions in lung and lymph nodes. We concluded that lesions that were not visualized in bovine tuberculin skin test reagents may occur and are related mainly to the stage of the disease, insufficient time to detect the lesions, and nonspecific reactions to other mycobacteria.
\end{abstract}

KEYWORDS: Mycobacterium bovis; slaughter; skin test. 
A tuberculose causada pelo Mycobacterium bovis é uma zoonose cujo hospedeiro primário é o bovino (OIE, 2009). A doença se caracteriza pelo desenvolvimento progressivo de lesôes nodulares denominadas tubérculos, que podem se localizar em qualquer órgão ou tecido (Souza, 1999). É uma importante causa de perdas econômicas, tanto em relação aos rebanhos individualmente como para a economia dos países onde ela ocorre. A infecção leva à diminuição de 10 a $20 \%$ da produção de leite e do ganho de peso do gado leiteiro e causa redução da fertilidade (Lilenbaum et al., 1998).

O diagnóstico da tuberculose bovina preconizado pela legislação brasileira recomenda a utilização de testes alérgicos, de tuberculinização intradérmica (Roxo 1996; Brasil, 2006). O teste cervical comparativo (TCC) é utilizado como diagnóstico confirmatório, pois permite eliminar a maior causa de reaçôes falso-positivas, que são as infecçóes por micobactérias ambientais ou pelas do complexo MAIS (Mycobacterium avium intracellulare scrofulaceum), que não são patogênicas para os bovinos, entretanto provocam reaçóes inespecíficas à tuberculinização (NeILl et al., 1988; Jorge, 2001).

Casos da doença têm ganhado cada vez mais destaque nas regióes do Alto Paranaíba e Triângulo Mineiro, no estado de Minas Gerais. Chama-se a atenção para a sua ocorrência principalmente em rebanhos de exploração leiteira. $\mathrm{O}$ teste intradérmico, aliado ao exame macroscópico nas linhas de inspeção dos abatedouros, tem alcançado bons resultados pelos programas de controle, quando implementados em regiôes com alta prevalência da doença (CoRner, 1994). Em alguns casos deve-se considerar que pode ocorrer uma correlação inversa entre os achados patológicos e a resposta ao teste tuberculínico, visto que animais com forte resposta ao PPD (Purified Protein Derivative) podem apresentar pouca ou nenhuma lesão evidente (FIRDESSA et al., 2012).

A não ocorrência de lesóes sugestivas de tuberculose em bovinos positivos no teste tuberculínico é um fato que ainda causa dúvida entre médicos veterinários de campo e proprietários. A falta de informaçóes sobre os diferentes estágios da fisiopatologia da tuberculose, aliada às dificuldades impostas pela inspeção visual, coloca em risco a credibilidade do diagnóstico tuberculínico. Diante disso, o objetivo deste trabalho foi analisar a frequência de lesóes macroscópicas sugestivas de tuberculose em carcaças de bovinos reagentes ao teste tuberculínico.

Foram examinadas 140 carcaças de bovinos positivos no TCC. O estudo foi conduzido em dois frigoríficos com Serviço de Inspeção Estadual no 3957 e Serviço de Inspeção Municipal no 102, localizados nos municípios de São Gotardo e Uberlândia, Minas Gerais. Os animais com idade entre 6 meses e 15 anos eram provenientes de rebanhos de exploração leiteira, procedentes de 5 propriedades localizadas nos municípios de Perdizes, Patos de Minas, Lagoa Formosa e Uberlândia, Minas Gerais.
Durante a inspeção post mortem das carcaças realiza$\mathrm{da}$ de acordo com as normas vigentes no Regulamento de Inspeção Industrial e Sanitária de Produtos de Origem Animal (Brasil, 1962), as lesóes sugestivas de tuberculose foram registradas e fotografadas. Foram inspecionados carcaça, linfonodos mediastínicos, fígado e pulmão.

Este trabalho foi realizado conforme os princípios éticos da experimentação animal estabelecidos pelo Comitê de Ética na Utilização de Animais (CEUA) da Universidade Federal de Uberlândia sob o protocolo no 054/12.

Durante a inspeção sanitária verificaram-se que dos 140 bovinos positivos no TCC, 78 (55\%) apresentaram algum tipo de lesão macroscópica sugestiva de tuberculose. A sensibilidade do exame é de 72 a $78 \%$, e a especificidade é de 92 a 99\% (OPAS, 1992). Os fatores que podem interferir na sensibilidade do teste são: a dose de tuberculina utilizada, os critérios de interpretação do teste, intervalo pós-infecção e pós-parto, variaçôes impostas pelo operador, desnutrição, entre outros (O'ReILly; Daborn, 1995). Animais infectados por $M$. avium, $M$. tuberculosis, M. avium subsp. paratuberculosis, Nocardia farcinius ou outras micobactérias podem ser reativos ao PPD bovino. Por esse motivo, o TCC é realizado com a finalidade de reduzir a ocorrência de tais reaçóes cruzadas (Collins et al., 1994).

Dentre as carcaças que apresentaram algum tipo de lesão macroscópica sugestiva de tuberculose, 38 (49\%) ocorreram exclusivamente nos linfonodos mediastínicos, 22 (28\%) no fígado e 11 (14\%) no pulmão; 5 (6\%) carcaças apresentaram lesôes no fígado, pulmão e linfonodos, e $2(4 \%)$ apresentaram lesões no pulmáo e linfonodo mediastínico. As lesôes visualizadas foram nódulos granulomatosos de aspecto purulento ou caseoso, com presença de cápsula fibrosa e em alguns casos apresentaram ainda calcificação no centro da lesão, evidenciada pelo ranger da faca ao corte (Fig. 1). Cinco carcaças (6\%) apresentaram quadro de tuberculose generalizada (tuberculose miliar) com nódulos de 1 a $3 \mathrm{~cm}$ distribuídos por toda a extensão da carcaça. Em 10,7\% dos casos observou-se ainda aumento de volume dos linfonodos mediastínicos.

Em 62 (45\%) carcaças não foram detectadas lesóes sugestivas de tuberculose ao exame macroscópico. Situaçôes em que os bovinos positivos aos testes tuberculínicos não apresentam lesões visíveis à necropsia podem estar relacionadas aos diferentes estágios de evolução da doença (Souza et al., 1999; Medeiros et al., 2012). De acordo com Medeiros et al. (2012), a resposta imune é diferente em infecçóes recentes e avançadas, o que permite a identificação entre animais cronicamente ou recentemente infectados. Nesse caso, a não observação de lesôes ao abate em animais positivos na tuberculinização não quer dizer que se trata de reação falso-positiva, pois as lesóes poderiam estar 

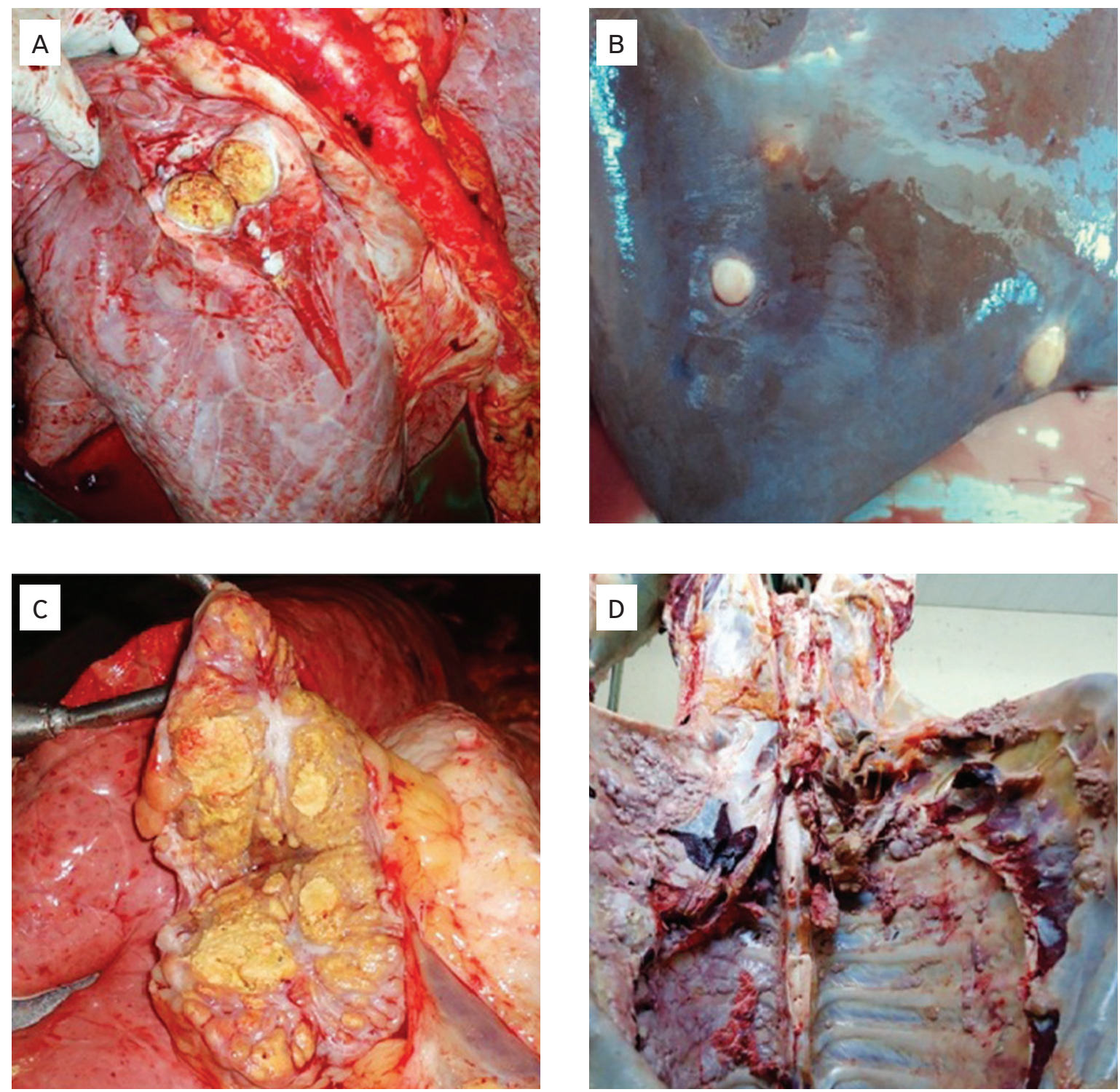

Figura 1. Lesões nodulares típicas de tuberculose em órgãos e carcaça de bovinos positivos no teste cervical comparativo. São Gotardo, Minas Gerais, 2012. (A) Pulmão apresentando lesão nodular com cerca de $3,0 \mathrm{~cm}$ de diâmetro, de cor amarelada, envolvido por cápsula fibrosa e contendo exsudato com aspecto caseoso em seu interior; (B) fígado com nódulos de $1 \mathrm{a} 3 \mathrm{~cm}$ de diâmetro; (C) aumento de volume de linfonodo mediastínico com processo inflamatório granulomatoso contendo exsudato de aspecto caseoso a purulento em seu interior; (D) carcaça com aspecto de tuberculose generalizada, apresentando lesões nodulares por toda a extensão da carcaça.

em estágios iniciais de evolução e por isso não foram detectadas pelo exame macroscópico.

Outro aspecto que deve ser levado em consideração é o tempo destinado para a inspeção sanitária, que pode ter sido insuficiente para detectar todas as lesōes. Segundo Menzies; NeILl (2000), o tempo destinado para a rotina de inspeção de carnes pode ser insuficiente para identificar lesōes discretas, e esse fato é comprovado quando não se identificam lesóes ao abate de animais reagentes. De acordo com Corner (1994), a inspeçâo de rotina só identifica cerca de $47 \%$ das lesões tuberculosas macroscopicamente detectáveis. Por isso, a inspeção mais detalhada poderia contribuir para a identificação das lesões tuberculosas durante o abate.

A frequência de animais tuberculina positivo com lesóes macroscópicas foi de 55\% (78/140), taxa inferior ao reportado por FrágUAS et al. (2008), que observaram 72\% (70/97) das carcaças com lesóes, e superior ao relatado por Pinto et al. (2004), que foi de 44\% (15/34) em bovinos reagentes à tuberculinização. Considerando-se que 58\% dos animais infectados com tuberculose apresentam lesōes únicas (Corner et al.,1990), a inspeção mais detalhada de linfonodos, incluindo os da cabeça, torácicos, mesentéricos 
e da carcaça, bem como baço, rim, úbere e órgãos genitais aumenta a possibilidade dessas virem a ser visualizadas (Corner, 1994).

Atribui-se ainda a essa frequência (55\%) o fato dos linfonodos parotídeos e retrofaríngeos não serem examinados na rotina de abate de um dos frigoríficos onde ocorreu o descarte desses animais. Trabalhos anteriores apontam o envolvimento dos linfonodos retrofaríngeos $(22,9$ a $49,2 \%)$ nas lesóes de tuberculose (Corner et al., 1990; Milian-Suazo et al., 2000). Segundo Corner et al. (1990), durante a inspeção sanitária em abatedouros, nos animais em que foi observada apenas uma lesão causada por $M$. bovis, o linfonodo retrofaríngeo foi o local mais afetado, correspondendo a $43,9 \%$ dos casos avaliados.
Conclui-se que as lesóes não visualizadas em bovinos reagentes ao teste tuberculínico podem ocorrer e estariam relacionadas principalmente ao estágio de evolução da doença, tempo insuficiente na inspeção post mortem para sua detecção, bem como reaçôes inespecíficas para outras micobactérias.

\section{AGRADECIMENTOS}

Os autores agradecem o auxilio financeiro do Conselho Nacional de Desenvolvimento Científico e Tecnológico (CNPq), da Coordenação de Aperfeiçoamento de Pessoal de Nível Superior (CAPES) e da Fundação de Amparo à Pesquisa do estado de Minas Gerais (FAPEMIG).

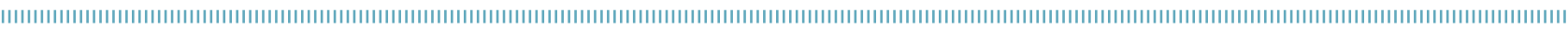

\section{REFERÊNCIAS}

BRASIL. Ministério da Agricultura. Regulamento da Inspeção Industrial e Sanitária de Produtos de Origem Animal. Brasília: Ministério da Agricultura, 1962. p.44-45.

BRASIL. Ministério da Agricultura, Pecuária e Abastecimento. Programa Nacional de Controle e Erradicação da Brucelose e Tuberculose Animal-PNCEBT. Brasília: MAPA, 2006. 188p.

COLLINS, D.M.; RADFORD, A.J.; LISLE, G.W.; JACOB, H.B. Diagnosis and epidemiology of bovine tuberculosis using molecular biological approaches. Veterinary Microbiology, v.40, n. 1-2, p.83-94, 1994.

CORNER, L.; MELVILLE, L.;MCCUBBIN, K.;SMALL, K.J.;MCCORMICK, B.S.; WOOD, P.R.; ROTHEL, J.S. Efficiency of inspection procedures for detection of tuberculous lesions in cattle. Australian Veterinary Journal, v.67, n.11, p.389-392, 1990.

CORNER, L.A. Post mortem diagnosis of Mycobacterium bovis infection in cattle. Veterinary Microbiology, v.40, n.1-2, p.5363, 1994.

FIRDESSA, R.; TSCHOPP, R; WUBETE, A.; SOMBO, M.; HAILU, E.; ERENSO, G.; KIROS, T.; YAMUAH, L.; VORDERMEIER, M.; HEWINSON, R.G.; YOUNG, D.; GORDON, S.V.; SAHILE, M.; ASEFFA, A.; BERG, S. High prevalence of bovine tuberculosis in dairy cattle in Central Ethiopia: implications for the dairy industry and public health. PLoS One, v.7, n. 12, e52851, 2012.

FRÁGUAS, S.A.; CUNHA-ABREU, M.S.; FERREIRA, A.M.R.; MARASSI, C.D.; OELEMANN, W.; FONSECA, L.S.; FERREIRA, R.; LILENBAUM, W. Estudo comparativo de métodos complementares para o diagnóstico da tuberculose bovina em animais reagentes à tuberculinização. Revista Brasileira de Ciência Veterinária, v.15, n.3, p.117-121, 2008.
JORGE, K.S.G. Aplicação de testes específicos e presuntivos para o diagnóstico da tuberculose bovina no estado de Mato Grosso do Sul, Brasil. 2001. 69f. Dissertação (Mestrado) - Fundação Oswaldo Cruz, Universidade Federal de Mato Grosso do Sul, Campo Grande, 2001.

LILENBAUM, W.; SCHETTINNI, J.; RIBEIRO, E.R.; SOUZA, G.N.; MOREIRA, E.C.; FONSECA, L.S. Tuberculose bovina: prevalência e estudo epidemiológico em treze propriedades de diferentes sistemas de produção na Região dos Lagos do Estado do Rio de Janeiro. Revista Brasileira de MedicinaVeterinária, v.20, n.3, p.120-123, 1998.

MEDEIROS, L.S.; MARASSI, C.D.; FIGUEIREDO, E.E.S.; LEITE, J.; FERREIRA, A.M.R.; LILENBAUM, W.; Assessing the histopathology to depict the different stages of bovine tuberculosis infection in a naturally infected herd. Pesquisa Veterinária Brasileira, v.32, n.2, p.135-139, 2012.

MENZIES, F.D.; NEILL, S.D. Cattle-to-cattle transmission of bovine tuberculosis. Veterinary Journal, v.160, n.2, p.92$106,2000$.

MILIAN-SUAZO, F.; SALMAN, M.D.; RAMIREZ, C.; PAYEUR, J.B.; RHYAN, J.C.; SANTILLAN, M. Identification of tuberculosis in cattle slaughtered in Mexico. American Journal of Veterinary Research, v.61, n. 1, p.86-89, 2000.

NEILL, S.D.; HANNA, J.; O'BRIEN, J.J.; MCCRACKEN, R.M. Excretion of Mycobacterium bovis by experimentally infected cattle. The Veterinary Record, v.123, n.13, p.340343, 1988.

O'REILLY, L.M.; DABORN, C.J. The epidemiology of Mycobacterium bovis infections in animals and man: a review. Tubercle and Lung Disease, v.76, s.1, p.1-46, 1995. 
OPAS - ORGANIZACION PANAMERICANA DE LA SALUD. Plan de acción para la erradicación de la tuberculosis bovina en las Américas. Coahuila: OPAS/OMS, 1992.

OIE - WORLD ORGANISATION FOR ANIMAL HEALTH. Manual of Diagnostic Tests and Vaccines for Terrestrial Animals 2009. Paris: OIE, 2009. Disponível em: http://www.oie.int/fileadmin/Home/eng/ Health_standards/tahm/A_index.htm. Acesso em: 18 set. 2014.

PINTO, P.S.A.; VILORIA, M.I.V.; FARIA, J.E.; ALMEIDA, L.P. Avaliação do desempenho dos exames anatomopatológico e histopatológico na inspeção post mortem de bovinos suspeitos ou reagentes à prova de tuberculinização. Revista Brasileira de Ciência Veterinária, v.11, n.1-2, p.27-31, 2004.

ROXO, E. Tuberculose bovina: revisão. Arquivos do Instituto Biológico, v.63, n.2, p.91-97, 1996.

SOUZA, A.V.; SOUSA, C.F.A.; SOUZA, R.M.; RIBEIRO, R.M.P.; OLIVEIRA, A.L.A. importância da tuberculose bovina como zoonose. Revista Higiene Alimentar, v.13, n.59, p.22-27, 1999. 